\title{
Effects of Sulfonylureas on the Synthesis and Secretion of Plasminogen Activator from Bovine Aortic Endothelial Cells
}

\author{
Be-Sheng Kuo, Gil Korner, and Thorir D. Bjornsson \\ Division of Clinical Pharmacology, Department of Medicine, Jefferson Medical College, Thomas Jefferson University, Philadelphia, \\ Pennsylvania 19107; and Division of Clinical Pharmacology, Departments of Medicine and Pharmacology, \\ Duke University Medical Center, Durham, North Carolina 27710
}

\begin{abstract}
The effects of sulfonylureas on the production of plasminogen activator (PA) and antiactivator (PAI) were investigated using bovine aortic endothelial cells. All compounds studied stimulated PA release (1.3- to 5.2-fold), with glipizide being the most potent, followed by tolazamide, chlorpropamide, and tolbutamide, in that order, while glyburide was the least effective. Both tissue-type and urokinase-type PA production was enhanced. Studies using metabolic inhibitors indicated that both RNA and protein syntheses are required for the sulfonylureamediated stimulation of PA release. In addition to continuous release of the two PAs, there was also a continuous release of a single PAI, which did not show an increase after the sulfonylureas. These results suggest that, in addition to their beneficial effects in the treatment of diabetes mellitus, some sulfonylurea compounds may also have significant thrombolytic effects. These results also suggest that pharmacological enhancement of PA production by vascular endothelial cells may be a promising antithrombotic mechanism.
\end{abstract}

\section{Introduction}

The plasma fibrinolytic system is responsible for the in vivo lysis of blood clots. Circulating plasminogen activators (PA), which are essential for the normal activation of the fibrinolytic system (1), have been thought to originate mainly from the vascular endothelium $(2,3)$. In addition to normal levels of PA, normal fibrinolytic activity depends on normal levels of plasminogen and is modified by inhibitors of plasmin and PA and by the affinity of these proteins to the fibrin clot $(1,4)$. Decreased fibrinolytic activity of plasma has been found to be associated with an increased risk of thromboembolic events in both the venous and arterial systems (5). The underlying cause in many instances appears to involve abnormally low levels of circulating PA. However, in spite of this association between low levels of PA and enhanced thromboembolic risk, there is limited data available regarding the mechanisms responsible

Received for publication 4 August 1986 and in revised form 13 October 1987.

1. Abbreviations used in this paper: BAE, bovine aortic endothelial (cells); PA, plasminogen activator; PAI, plasminogen activator inhibitor; tPA, tissue plasminogen activator; UK, urokinase.

J. Clin. Invest.

(c) The American Society for Clinical Investigation, Inc.

0021-9738/88/03/0730/08 $\$ 2.00$

Volume 81, March 1988, 730-737 for the regulation of PA synthesis and its release into the circulation $(6,7)$.

Sulfonylurea compounds have been widely used clinically as oral hypoglycemic agents because of their stimulating effects on the secretion of insulin by the beta cells of the islets of Langerhans in the pancreas. In addition to this pharmacologic effect, they have also been shown to have a fibrinolytic effect $(6,8,9)$. The sulfonylureas that have been reported to enhance plasma fibrinolytic activity in man include tolbutamide, chlorpropamide, and gliclazide. In fact, these agents have been shown to elevate the low fibrinolytic activity often observed in diabetic patients (10). In studies on the effects of sulfonylureas on the fibrinolytic system, the fibrinolytic effect has been determined by clot lysis tests. Since such tests do not enable mechanistic interpretations, the mechanism of action underlying the fibrinolytic effect of sulfonylureas is not known.

The purpose of the present investigation was to elucidate the mechanism of action of the enhanced fibrinolytic effect of the sulfonylureas using cultured bovine aortic endothelial cells. The underlying hypothesis was that the sulfonylureas stimulate the synthesis and secretion of PA from these cells. Such a mechanism, in addition to providing additional benefits to diabetic patients, might be a promising new antithrombotic drug mechanism.

\section{Methods}

Materials. Purified melanoma tissue plasminogen activator (tPA) (11) and urokinase (UK) were a gift from Dr. H. Berger (Burroughs Wellcome Co., Research Triangle Park, NC). The tPA was standardized against an international standard and contained $30 \mathrm{U} / \mathrm{ml}$. Plasminogen was prepared from human plasma by affinity chromatography on lysine-Sepharose (Sigma Chemical Co., St. Louis, MO) as previously described (12), with a modification involving a wash with $0.5 \mathrm{M}$ $\mathrm{NH}_{4} \mathrm{SCN}$ before the elution with $\epsilon$-aminocaproic acid. Fibrinogen was obtained from Kabi Diagnostica (Stockholm, Sweden) and ${ }^{125}$ I-labeled fibrinogen (Ibrin, sp act $154 \mu \mathrm{Ci} / \mathrm{mg}$ ) was purchased from Amersham Corporation (Arlington Heights, IL). Thrombin was obtained from Sigma Chemical Co. Purified fibroblast growth factor (FGF) was generously donated by Dr. D. Gospodarowicz (University of California, San Francisco, CA). Fetal calf serum (FCS) and Dulbecco's modified Eagles medium (DME) were obtained from Gibco (Grand Island, NY). Tissue culture dishes were from Costar Co. (Cambridge, MA). Electrophoresis equipment and reagents were from Bio-Rad Laboratories (Richmond, CA). Goat normal IgG, goat anti-human UK and antimelanoma tPA IgGs were obtained from American Diagnostica (Greenwich, CT). Rabbit anti-goat IgG was from Sigma Chemical Co.

Tolbutamide, tolazamide, and glyburide were gifts from Dr. R. F. Carlson (Upjohn Co., Kalamazoo, MI). Chlorpropamide and glipizide were gifts from Mr. N. Belcher (Pfizer Inc., Groton, CT). Stock solutions $(10 \mathrm{mM})$ were made in DME for tolbutamide and tolazamide, in $50 \%$ ethanol/50\% $50 \mathrm{mM}$ phosphate buffer, $150 \mathrm{mM} \mathrm{NaCl}$, pH 7.4 (PBS), for glyburide and chlorpropamide, and in $0.1 \mathrm{~N} \mathrm{NaOH}$ in PBS 
for glipizide, and stored at $-20^{\circ} \mathrm{C}$ in small aliquots. Actinomycin D was obtained as an injection solution from Merck Sharp \& Dohme Co. (West Point, PA). Cycloheximide was purchased from Sigma Chemical $\mathrm{Co}$. and was dissolved in distilled water. Dilutions of all chemicals were made in DME supplemented with $2 \mathrm{mM}$ glutamine, $17 \mathrm{mM} \mathrm{NaHCO}_{3}$ and $1 \%(\mathrm{vol} / \mathrm{vol})$ antibiotic-antimycotic mixture (penicillin, streptomycin, and amphotericin B; Sigma Chemical Co.).

Cell culture. Bovine aortic endothelial (BAE) cells were isolated by scraping and cloned using a ring method as described (13), with minor modifications. Cells were grown in DME culture medium containing $10 \%$ heat-inactivated FCS and $2 \mathrm{mM}$ glutamine. Cell growth was supported with $50 \mathrm{ng} \mathrm{FGF} / \mathrm{ml}(14)$. The cells were incubated at $37^{\circ} \mathrm{C}$ in a humidified $95 \%$ air $/ 5 \% \mathrm{CO}_{2}$ atmosphere. They were routinely passed with a split ratio of $1: 10$. The cells exhibited typical endothelial cell morphology, involving confluent monolayers of polygonal, closely aposed cells with "cobblestone" morphology, and stained positively for factor VIII-related antigen (15). BAE cells at passages 13-17 were used in these studies. The PA profiles did not exhibit qualitative differences at the different passages studied. Furthermore, cell cultures at earlier passages (passages 3,5, and 8) exhibited the same PA profiles and showed similar responses after the sulfonylureas.

The endothelial cells used in the experiments were plated at $3 \times 10^{4}$ cells/well on Costar 24-well tissue culture plates and grown without FGF support in a culture medium containing $10 \%$ heat-inactivated FCS. Confluence, verified by a plateau growth curve and featured with a mosaic "cobblestone" pattern, was usually achieved at the fifth or sixth day after cell inoculation. Cell density at confluence was $5.5 \times 10^{4}$ cells $/ \mathrm{cm}^{2}$. The confluent cultures were washed once with DME and the medium replaced with $0.45 \mathrm{ml}$ of the same medium and $50 \mu \mathrm{l}$ of a sulfonylurea compound (final concentration $10^{-4}$ to $10^{-11} \mathrm{M}$ ). Control cultures contained DME alone or DME containing $0.05 \%$ ethanol or $0.001 \mathrm{~N} \mathrm{NaOH}$; the latter were for experiments where the sulfonylureas had to be dissolved in these solvents. Controls containing ethanol and $\mathrm{NaOH}$ under the experimental conditions did not affect PA activity as compared with the cultures containing only DME. For the dose-response studies, cultures were incubated for $24 \mathrm{~h}$, while for the time course studies cells were incubated with the sulfonylureas at $10^{-8}$ $M$ for 2, 6, 12, 24, and $48 \mathrm{~h}$. After harvesting the conditioned medium, the cultures were rinsed twice with ice-cold PBS and lysed with $150 \mu \mathrm{l}$ of $0.75 \%$ SDS in $100 \mathrm{mM}$ Tris- $\mathrm{HCl}, \mathrm{pH} 7.4$. Samples were frozen at $-20^{\circ} \mathrm{C}$ until analyzed for extracellular and cell-associated PA activity by the fibrin plate method. Protein content of control lysates was determined by the method of Smith et al. (16), using bovine serum albumin as the standard.

Fibrin plate assay. A sensitive and reproducible fibrin plate method has been optimized on Costar 96-well tissue culture plates for the determination of PA activity, using modifications of previously described methods $(17,18) .{ }^{125} \mathrm{I}$-labeled and unlabeled fibrin monomers were prepared from ${ }^{125}$ I-fibrinogen and fibrinogen by clotting with thrombin ( $25 \mathrm{NIH} \mathrm{U/100} \mathrm{mg} \mathrm{fibrinogen)} \mathrm{in} \mathrm{a} \mathrm{calcium-free} \mathrm{solu-}$ tion and dissociating the clot with $0.02 \mathrm{M}$ acetic acid, $\mathrm{pH} 3$, containing $0.02 \%$ sodium azide. Each well of a Costar 96-well plate was coated with a $35 \mu \mathrm{l}$ mixture of ${ }^{125} \mathrm{I}$-fibrin $(15,000 \mathrm{cpm}$ per well) and unlabeled fibrin (1.25 $\mu \mathrm{g}$ per well) and dried at $56^{\circ} \mathrm{C}$ for $3-18 \mathrm{~h}$. tPA standards $(25 \mu \mathrm{l})$ and unknown samples ( $25 \mu \mathrm{l}$ after dilution with DME) were first treated on an uncoated 96-well plate with $25 \mu \mathrm{l}$ of $1.5 \%$ SDS in 100 $\mathrm{mM}$ Tris- $\mathrm{HCl}, \mathrm{pH} 7.4$ (final concentration $0.75 \% \mathrm{vol} / \mathrm{vol}$ ) and incubated in a water bath at $37^{\circ} \mathrm{C}$ for $30 \mathrm{~min}$, then treated with $50 \mu \mathrm{l}$ of $15 \%$ Triton X-100 in $100 \mathrm{mM}$ Tris- $\mathrm{HCl}, \mathrm{pH} 7.4$ (final concentration $7.5 \%$, vol/vol). After brief, gentle shaking, 50- $\mu$ l aliquots of the resulting mixtures were transferred with multipipetter to the ${ }^{125}$ I-fibrin-coated plate after the addition to each well of $180 \mu \mathrm{l}$ of an assay buffer containing $1 \mu \mathrm{g}$ of purified human plasminogen. The assay buffer consisted of $0.1 \mathrm{M}$ Tris- $\mathrm{HCl}, \mathrm{pH} 8.0,1 \mathrm{mM}$ EDTA, and $0.1 \%$ gelatin.

Standard curves were generated for each 96-well plate, consisting of tPA concentrations of 1-10 (in increments of $1 \mathrm{mU}$ per well), 12, 16, and $20 \mathrm{mU}$ per well. Dilutions of tPA for the standard curves and of unknown samples were made in DME. The plate was then incubated at $37^{\circ} \mathrm{C}$ on a water bath for $2 \mathrm{~h}$. Fibrinolysis was measured as the percentage of total releasable radioactivity released into the assay buffer. Total releasable radioactivity was determined as the sum of radioactivity released into the buffer and radioactivity released after treatment with $100 \mu \mathrm{l}$ of $1 \mathrm{mg} / \mathrm{ml}$ trypsin for $15 \mathrm{~min}$ at $37^{\circ} \mathrm{C}$. The standard curves were usually linear between 10 and $65 \%$ of the total releasable radioactivity in the well, corresponding to a range of 1-10 $\mathrm{mU}$ of tPA. Plasminogen-independent release was approximately $5 \%$, as based on the intercept values. Calibration curves were constructed using linear regression analysis $(r>0.99)$, and the secreted and cellular PA activities of unknown samples were computed from these curves. Calibration curves for UK were similar to those for tPA. A typical standard curve under the experimental conditions described is presented in Fig. 1.

$S D S-P A G E$. To determine whether tissue-type PA or UK, or both, contributed to the observed increases in PA activities after the sulfonylureas, conditioned media from control and sulfonylurea-treated samples were subjected to SDS-PAGE using a modification of previously described methods $(19,20) .10 \%$ acrylamide gel was used (slab size 60 $\times 90 \times 1.5 \mathrm{~mm}$ ) and copolymerized with $0.1 \%$ gelatin in the presence of $0.001 \%$ plasminogen purified from human plasma. After the run and treatment with Triton X-100 to remove SDS, PA activity was

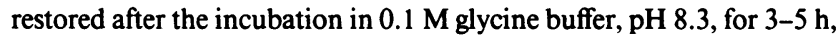
and zone lysis was visualized by staining with amido black. No lysis zones were observed in the absence of plasminogen. The molecular weight markers used, phosphorylase $b(94,000)$, bovine serum albumin $(67,000)$, ovalbumin $(43,000)$, carbonic anhydrase $(30,000)$, and soybean trypsin inhibitor $(20,000)$, were obtained from Pharmacia Fine Chemicals (Piscataway, NJ).

Immunoprecipitation. The identity of the PA species observed on the SDS-PAGE zymograms was further determined using immunoprecipitation methods. The conditioned medium, standard human melanoma tPA, and human UK were incubated at $-4^{\circ} \mathrm{C}$ for $4 \mathrm{~h}$ or overnight separately with goat normal IgG, goat anti-human UK, and antimelanoma tPA IgGs in $0.1 \mathrm{M}$ Tris- $\mathrm{HCl}$ and $1 \mathrm{mM}$ EDTA, $\mathrm{pH} 8.0$, containing $0.1 \%$ SDS. All IgGs were in a final concentration of 200 $\mu \mathrm{g} / \mathrm{ml}$. The rabbit anti-goat IgG was then added in a 10-fold excess of the goat IgGs to the samples, and incubated at $-4^{\circ} \mathrm{C}$ for $4 \mathrm{~h}$ or overnight. The formed precipitates were washed by vortexing three times with $1-\mathrm{ml}$ aliquots of the same Tris-EDTA buffer. The washed pellets were then dissolved with 5\% SDS in water and subjected to SDS-PAGE with copolymerized plasminogen and gelatin as described above.

Reverse fibrin autography. Potential PA inhibitors (PAI) released from the endothelial cells were evaluated by the reverse fibrin autography method as described $(21,22)$ with minor modifications. The slab gel $(60 \times 90 \times 7.5 \mathrm{~mm})$ was soaked with $2.5 \%$ Triton X-100 at $37^{\circ} \mathrm{C}$ for $1 \mathrm{~h}$ after the run to remove SDS. The gel was then applied to the fibrin-agar indicator film consisting of $2.5 \mathrm{mg} / \mathrm{ml}$ human fibrino-

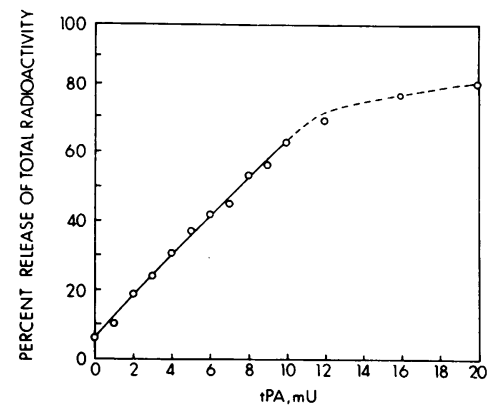

Figure 1. A representative calibration curve for PA activity showing the linear relationship between the amount of tPA added to each well of the fibrin plate and the percent release of total radioactivity. The solid line represents the best-fitted linear regression line $(r=0.994)$. A curvature occurred at amounts of tPA $>10$ $\mathrm{mU}$ as shown by the dashed line. 
gen (Kabi grade L), $0.2 \mathrm{U} / \mathrm{ml}$ thrombin (Sigma Chemical Co.), $1 \%$ low molecular weight agarose (Bio-Rad Laboratories), $25 \mu \mathrm{g} / \mathrm{ml}$ purified human plasminogen, and $0.5 \mathrm{U} / \mathrm{ml} \mathrm{UK}$. All these materials were prepared in PBS, pH 7.4. The indicator film was incubated at $37^{\circ} \mathrm{C}$ in a moisture chamber and the lysis-resistant zones developing on the gel were photographed against a black background after 2-3 h of incubation.

\section{Results}

Kinetics of PA activity. The accumulation of extracellular and cell-associated PA activities from control and sulfonylureatreated cultured BAE cells was investigated after incubations of different durations. Fig. 2 shows the time course of PA activity in the supernatant medium in the presence of the five sulfonylureas at concentrations of $10^{-8} \mathrm{M}$. There was a clear lag time of $\sim 6 \mathrm{~h}$ in PA secretion, but subsequently there was a continuous release and accumulation of PA with time for a period of up to $48 \mathrm{~h}$. This was also seen for the control BAE cell cultures. At all time points after $6 \mathrm{~h}$ the sulfonylureatreated cultures secreted significantly more PA than the control cultures. However, there was no apparent lag time in cellular PA activity, and differences in cellular PA activity between control and sulfonylurea-treated cells were not seen until after $24 \mathrm{~h}$ of incubation (Fig. 3). Comparisons between extracellular and cell-associated PA showed that the enhancement in cellular PA was minor, indicating that most of the increased production of PA was secreted into the culture medium (Fig. 4). The observations from the time course studies also indicated that the confluent cells incubated with DME were viable beyond $48 \mathrm{~h}$. Based on these data the dose-response studies for all sulfonylureas were performed using 24 hour long incubations.

Concentration-response relationship. The relationships between concentrations of the five different sulfonylureas and the increases in PA secretion were determined using a series of concentrations ranging from $10^{-4}$ to $10^{-11} \mathrm{M}$ and confluent BAE cells after 24-h long incubations. The released PA activity in the control cells at that time was $32.4 \pm 3.0 \mathrm{U} / \mathrm{mg}$ cellular protein (mean \pm SEM, $n=6$ ). As is shown in Fig. 5 , all of the sulfonylureas tested enhanced the amount of PA activity released into the medium in a dose-dependent manner. However, there was an apparent difference among these compounds. For glipizide, tolazamide, and chlorpropamide, the dose-dependent increases in secreted PA activities reached

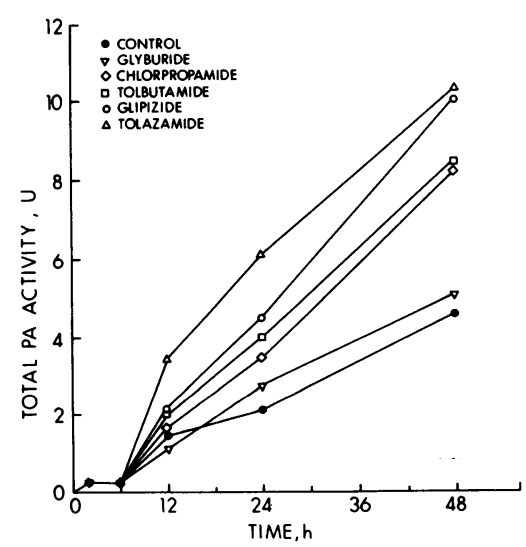

Figure 2. Time courses (average of two experiments) of PA activity per well secreted into the conditioned medium of confluent BAE cell cultures. Control cells and cells treated with five different sulfonylureas (10 $\mathrm{nM})$ were incubated for the indicated periods of time. Supernatants were harvested and analyzed for PA activity by the ${ }^{125}$ I-fibrin plate method as described in Methods.

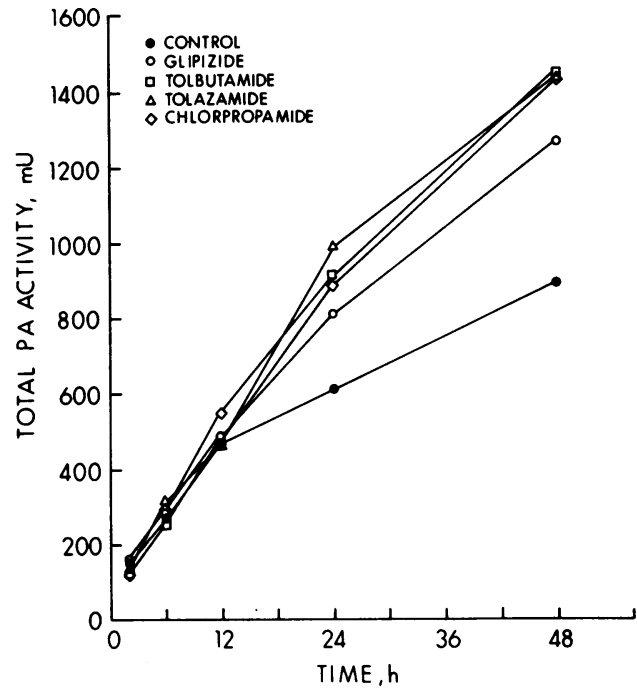

Figure 3. Time courses (average of two experiments) of PA activity per well in cellular extracts from confluent BAE cell cultures. Control cells and cells treated with four sulfonylureas $(10 \mathrm{nM})$ were incubated for the indicated durations of time. The cells were extracted for PA activity which was determined by the ${ }^{125}$ I-fibrin plate method as described in Methods.

maximum levels at $\sim 10^{-7}$ to $10^{-8} \mathrm{M}$, and the enhanced effect declined progressively as the concentration increased to $10^{-4}$ M. For these three compounds a significant increase in PA release was still seen at concentrations as low as $10^{-10}$ to $10^{-11}$ M. For tolbutamide and glyburide, however, the response of the BAE cells was less marked and the dose-response curve rose more slowly. In fact, in two of three separate experiments, no significant enhancement in PA release could be observed at concentrations of $10^{-9} \mathrm{M}$ for tolbutamide and glyburide. Since cell cultures treated with $10^{-4} \mathrm{M}$ glyburide (and chlorpropamide) contained $0.5 \%$ ethanol, the increased PA secretion observed at this concentration cannot be unequivocally proven to be sulfonylurea-induced, as ethanol at a concentration of

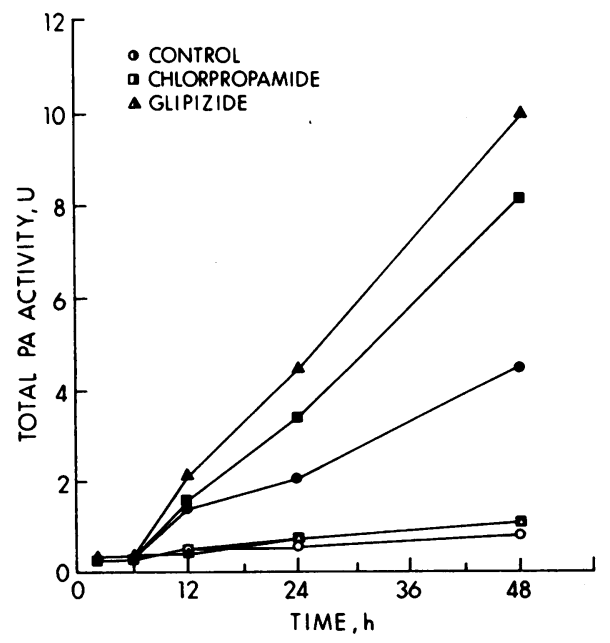

Figure 4. Comparison between time courses of released and cell-associated PA activities for control BAE cells and cells treated with glipizide and chlorpropamide (both $10 \mathrm{nM}$ ). Data were retrieved from Figs. 2 and 3. The open symbols represent the cell-associated PA activities and the closed symbols represent the PA activities in the supernatant medium. 

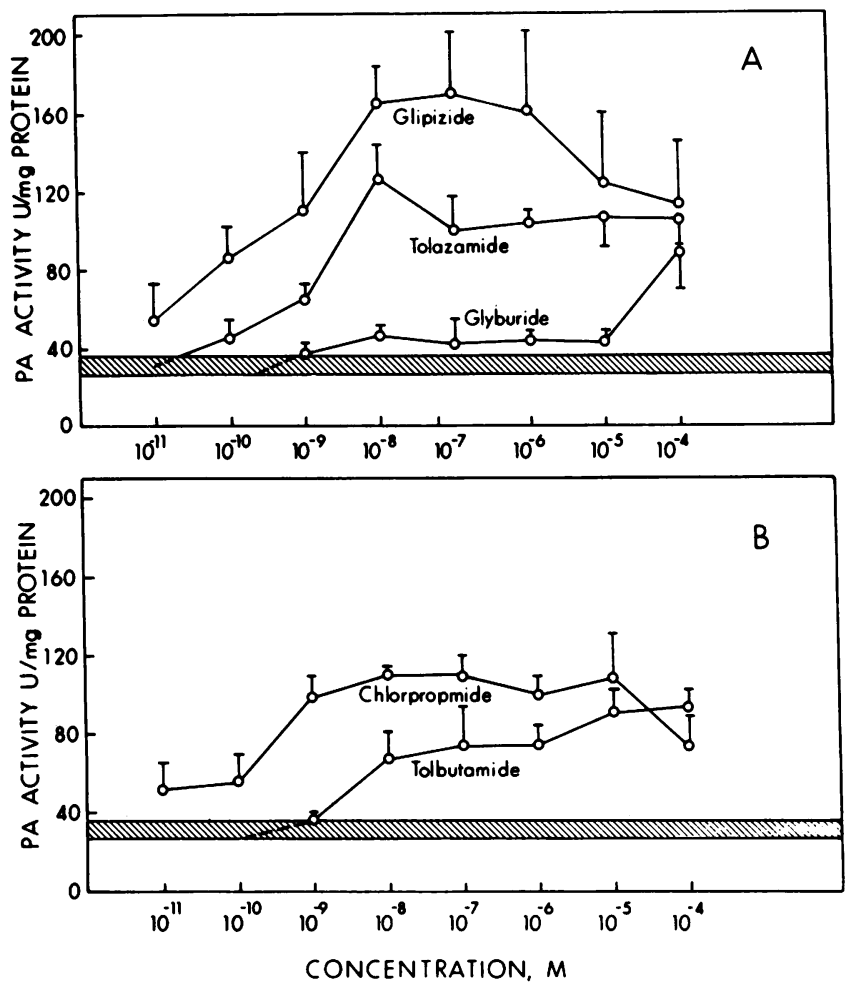

Figure 5. Concentrations vs. response relationships for sulfonylureainduced enhancement of tPA release in confluent BAE cell cultures. The supernatant medium was harvested after $24 \mathrm{~h}$ of incubation and analyzed for PA activity as described in Methods. The released PA activity was adjusted for the cellular protein concentration. Each data point represents the mean of six replicate samples from three separate experiments. The vertical bars indicate 1 SEM. The horizontal shaded area represents the mean \pm 1 SEM of the PA activity released from the control cells.

$0.5 \%$ has been reported to enhance PA release from endothelial cells (23).

Table I shows the relative potency of the five sulfonylurea compounds tested. The comparison is based on the maximum effect elicited by each compound compared with the PA activity released from the control cells. Glipizide was the most potent compound, causing more than five-fold increase in the PA release at a concentration of $10^{-7} \mathrm{M}$. Tolazamide, chlorpropa-

Table I. Relative Potency of Five Different Sulfonylureas with Respect to Stimulation of PA Secretion from Vascular Endothelial Cells

\begin{tabular}{lcc}
\hline \multicolumn{1}{c}{ Drug } & Relative potency & Drug concentration \\
\hline & & $M$ \\
Glipizide & 5.24 & $10^{-7}$ \\
Tolazamide & 3.94 & $10^{-8}$ \\
Chlorpropamide & 3.42 & $10^{-7}$ \\
Tolbutamide & 2.82 & $10^{-5}$ \\
Glyburide & 1.33 & $10^{-5}$ \\
\hline
\end{tabular}

The comparison is based on the maximal effects that the compounds induced after $24 \mathrm{~h}$ of incubation compared with the control. The concentration listed is that at the maximum effect. Values are based on averages of six replicate samples from three individual experiments. mide, and tolbutamide, in that order, all caused a three- to four-fold increase in PA release at concentrations between $10^{-5}$ and $10^{-8} \mathrm{M}$. Glyburide, however, was clearly by far the least potent sulfonylurea; the potencies of the two least potent compounds, glyburide and tolbutamide, were arbitrarily based on the response at a concentration of $10^{-5} \mathrm{M}$.

Increases in cell-associated PA were also observed after treatment with the sulfonylureas. At $24 \mathrm{~h}$ the cell-associated PA activity in the control cells was $9.7 \pm 2.7 \mathrm{U} / \mathrm{mg}$ protein (mean \pm SEM; $n=7$ ), indicating that at that time the cell-associated PA activity is less than one-third of that in the supernatant medium. The average PA activities at that time for the three most potent sulfonylureas, i.e., glipizide, tolazamide, and chlorpropamide, over the concentration range of $10^{-6}$ to $10^{-9}$ $M$ were $14.6 \pm 1.1,16.4 \pm 1.3$, and $14.5 \pm 2.0 \mathrm{U} / \mathrm{mg}$ protein, respectively. These increases in cell-associated PA represent only 1.5-1.7-fold increases over the control values, which is a much smaller increase than that observed for the released PA, which was four- to fivefold for these agents. This difference in relative increases in released and cell-associated PA activities is illustrated in Fig. 6, which shows the time course of PA activity relative to control for both released and cell-associated PA activity after treatment with $10 \mathrm{nM}$ glipizide. Although the two time courses are similar, the one for released PA activity is about three times as high as that for cell-associated PA activity.

Effects of metabolic inhibitors on PA activity. The increased synthesis and secretion of PA activity by the sulfonylureas was inhibited after coadministration of actinomycin D or cycloheximide (both $4 \mu \mathrm{g} / \mathrm{ml}$ ). Cell viability under these conditions was confirmed by trypan blue exclusion experiments. Table II shows the results when the three most potent compounds were tested. It can be seen that the secretion of PA was inhibited by $70-80 \%$, while the cell-associated PA was inhibited by $50-60 \%$. This decrease in both secreted and cell-associated PA activities indicates that both RNA and protein synthesis is required for the sulfonylurea-mediated stimulation of PA secretion.

$P A$ zymography. Fig. 7 shows a SDS-PAGE gel of the PAs released from the BAE cells into the supernatant medium. These gels have plasminogen and gelatin copolymerized enabling visualization of lysed bands corresponding to the approximate molecular weights of the individual plasminogen activators. In addition to accumulative activities observed for both control and tolazamide-treated cells after incubations for 16,24 , and $36 \mathrm{~h}$, multiple forms of PA produced by BAE cells were noted. The same PA pattern was observed for the other

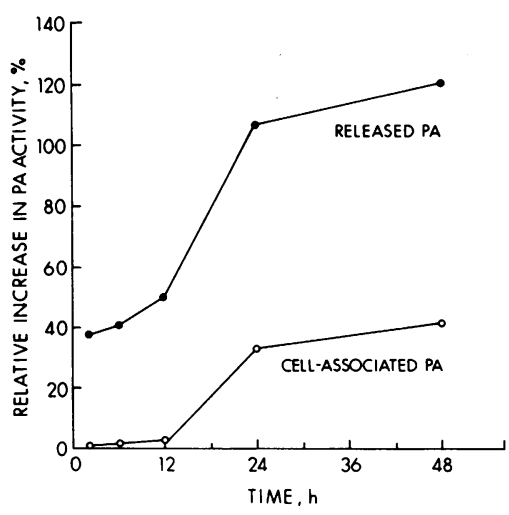

Figure 6. Time courses of percent increases in released and cell-associated PA activities from BAE cells by glipizide (10 nM). Both curves were obtained by subtracting released and cell-associated PA activity of glipizide-treated cells by the respective activities in control cells. The data points represent the average of two experiments. 
Table II. Effects of Actinomycin D and Cycloheximide on Sulfonylurea-induced PA Activities

\begin{tabular}{|c|c|c|c|c|c|c|}
\hline \multirow[b]{2}{*}{ Sulfonylurea } & \multicolumn{3}{|c|}{ Secreted PA } & \multicolumn{3}{|c|}{ Cellular PA } \\
\hline & Control & ACT & CHX & Control & ACT & CHX \\
\hline & \multicolumn{6}{|c|}{$m U / w e l l(\%)$} \\
\hline Tolazamide & 3,124 & $876(28)$ & 844 (27) & 646 & $273(42)$ & $242(37)$ \\
\hline Chlorpropamide & 3,454 & $1,052(30)$ & $948(27)$ & 660 & $307(47)$ & $329(50)$ \\
\hline Glipizide & 5,162 & $976(19)$ & $1,028(20)$ & 691 & $366(53)$ & 339 (49) \\
\hline
\end{tabular}

Actinomycin D (ACT) and cycloheximide (CHX), both $4 \mu \mathrm{g} / \mathrm{ml}$, were coadministered with the sulfonylureas (10 $\mathrm{nM}$ ) to confluent BAE cells and incubated for $24 \mathrm{~h}$. Results are the average of two experiments. Values in parentheses represent the percentage of control activities.

sulfonylureas. Both the control and sulfonylurea-treated cells secreted four distinct PA species. The PA pattern in whole-cell lysates was similar to that of the conditioned medium (data not shown). None of these comigrated with UK, but a band with an apparent molecular weight of 55,000 corresponded to purified melanoma tPA. Two upper bands were observed with apparent molecular weights around and >90,000; these are likely to represent PA-inhibitor complexes. The major band on the zymogram, however, corresponded to an apparent molecular weight of $\sim 40,000$. All of the bands seen on the gels for both the control and sulfonylurea-treated cells exhibited an increase in the lysis zones with time. Similarly, all of the bands increased after sulfonylurea treatment. This SDS-PAGE analysis provides evidence that the enhanced PA activity observed with the ${ }^{125}$ I-fibrin plate method was due to the increased levels of the PA species.

Immunoprecipitation. The identity of the PA species was determined by immunoprecipitation experiments followed by SDS-PAGE zymography. Fig. 8 illustrates that the 55,000band was immunoprecipitated by the anti-tPA antibody (lane 3) and comigrates with the human melanoma tPA standard (lane 5), while the major band, with a molecular weight of $\sim 40,000$, was immunoprecipated by the anti-UK antibody (lane 4), although it did not comigrate with standard human UK (lane 6). Note that the normal IgG did not precipitate any

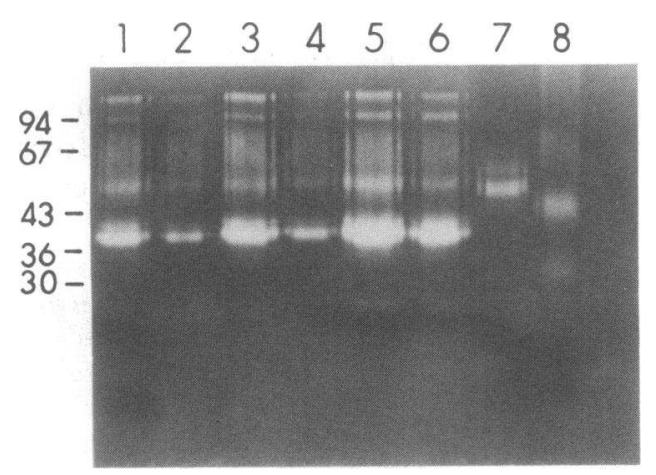

Figure 7. SDS-PAGE with copolymerized plasminogen and gelatin of the PAs released into the supernatant medium from control cells and cells treated with tolazamide $(10 \mathrm{nM})$ after incubation for $16 \mathrm{~h}$ (lanes 1 and 2), $24 \mathrm{~h}$ (lanes 3 and 4 ) and $36 \mathrm{~h}$ (lanes 5 and 6). Lanes 1,3 , and 5 represents tolazamide-treated samples, while lanes 2,4 , and 6 are from control cells. Lanes 7 and 8 have purified melanoma tPA and UK, respectively. The bands were subsequently visualized as described in Methods.
PA activity (lane 2). Of additional interest is the narrow lysis band in lane 4, i.e., immunoprecipitated by the anti-UK antibody, with a molecular weight of approximately 90,000 . This band most likely represents a UK-like PA-PAI complex. It should also be noted that a similar band could be detected in lane 3, i.e., immunoprecipitated by the anti-tPA antibody, if large volume of conditioned medium was loaded on the gel. These immunoprecipitation experiments thus indicate that the BAE cells secrete both IPA- and UK-type PA. Immunoprecipitation experiments were also carried out, where the conditioned medium was incubated with different dilutions of the above specific antibodies and then subjected to the ${ }^{125} \mathrm{I}$-fibrin plate assay. The results of these precipitation experiments further supported the existence of both tPA- and UK-type PA species as specific antibody-dependent decreases in PA activity were observed, in agreement with the above SDS-PAGE zymography findings (data not shown).

Reverse fibrin autography. Both control cells and cells treated with the sulfonylureas continuously secreted a single PAI species with a molecular weight of $\sim 45,000$. Fig. 9 shows a typical PAI zymogram obtained from the conditioned medium of control cells and cells treated with $10 \mathrm{nM}$ glipizide, which typically resulted in a visible decrease in the size of the opaque band corresponding to PAI, after both 24- and 48-h incubations. Similar results were also observed after the other sulfonylureas. Although the apparent reductions in PAI activity were not in proportion with the enhancements in PA activity, these observations nevertheless suggest that the sulfonyl-

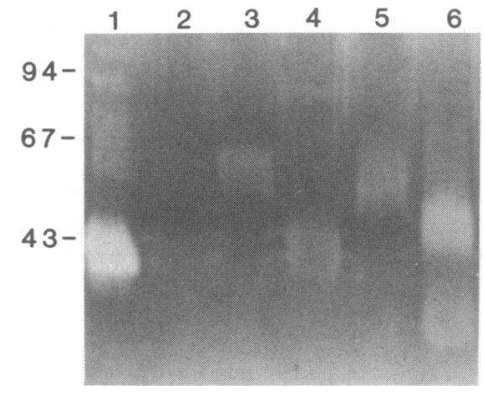

Figure 8. SDS-PAGE with copolymerized plasminogen and gelatin after immunoprecipitation as described in Methods. Lane 1 shows the results of conditioned medium of BAE cells treated with $10 \mathrm{nM}$ glipizide for $48 \mathrm{~h}$, which was not subjected to any immunoprecipitation, and thus represents the original sample. Lanes 2, 3, and 4 show the results after an aliquot of the same sample had been immunoprecipitated with normal IgG, antitPA, and anti-UK antibodies, respectively. Lanes 5 and 6 show the results after the human melanoma tPA and human UK standards, respectively, had been immunoprecipitated with the respective specific antibodies. The lysis zones were visualized as described in Methods. 


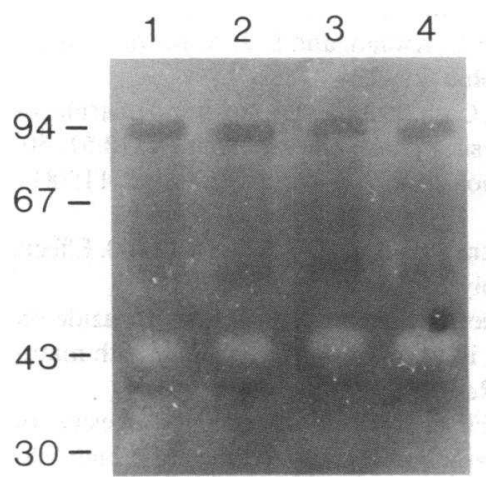

Figure 9. Reverse fibrin autography illustrating the release of PAI from control BAE cells (lanes 3 and 4) and cells treated with 10 nM glipizide (lanes 1 and 2) after incubation for $24 \mathrm{~h}$ (lanes 1 and 3) and $48 \mathrm{~h}$ (lanes 2 and 4). The PAI activity is indicated by the opaque zones, while the dark bands represent PA activities also visualized by the fibrin indicator film.

urea-mediated enhancement in PA activity may be contributed to by a decrease in PAI formation. Separate studies were carried out to investigate whether a fast-acting PAI was released from the cells. This involved mixing of the conditioned medium immediately after harvesting with the tPA and UK standards, which were added in excess, followed by reverse fibrin autography and fibrin plate assay. No quenching effects were observed with either assay.

\section{Discussion}

Although decreased fibrinolytic activity has been described in diabetic patients $(10,24,25)$ and hypoglycemic agents $(6,8,9$, $26,27)$ have been shown to increase plasma fibrinolytic activity, the mechanism underlying the fibrinolytic effect of these agents has not been elucidated. The results of the present investigation using BAE cells have demonstrated that sulfonylureas stimulate the synthesis and secretion of PAs, and thus suggest that that is the mechanism of action for the in vivo fibrinolytic effect of the sulfonylureas.

Time course studies in control and sulfonylurea-treated endothelial cells showed that after replacement with DME there was a delay of about $6 \mathrm{~h}$ before a significant increase in PA activity was observed; subsequently, there was an approximately linear increase in secreted PA with time. A similar delay has been described in thrombin-stimulated human endothelial cells (28), retinoic acid-treated synovial fibroblasts (29), and in synovial fibroblasts stimulated with mononuclear cell supernatant (17). However, no such delay was observed in cellular PA activity. Apparently, only a small fraction of synthesized PA is stored in the endothelial cells, as evidenced by the finding that after 24-h-long incubation, secreted PA activity was 3.3 times as high as cellular PA. This is in general agreement with findings in other cells $(28,29)$. Even after the sulfonylurea-enhanced rate of PA synthesis, there was only a modest increase in cellular PA compared with released PA. For example, glipizide at $10 \mathrm{nM}$ caused 5.2-fold increase in secreted PA at $24 \mathrm{~h}$ but only 1.5-fold increase in cellular PA, or expressed another way, released/cellular PA ratio was 3.3 in control cells, but 11.6 after glipizide. Thus, these results indicate that most of the stimulated PA is secreted out of the cells, and that secreted PA best reflects the effects of factors influencing PA synthesis.

The present studies have shown that the mechanism of action of the sulfonylurea-enhanced PA release by the endothelial cells involves enhanced RNA and protein synthesis. Coadministration of actinomycin $\mathrm{D}$ and cycloheximide resulted in significant reduction of sulfonylurea-induced PA re- lease. As sulfonylureas are used clinically for their hypoglycemic effect and they have been shown to increase fibrinolytic activity in vivo, it could be proposed that the fibrinolytic effect is mediated by changes in plasma insulin. However, the present cell culture studies, which were carried out in insulinfree medium, clearly indicate that the sulfonylureas have a direct action on endothelial cells to enhance the rate of synthesis of plasminogen activators. It should also be noted that preliminary studies with phenformin, a biguanide hypoglycemic agent, which has been reported to enhance fibrinolytic activity in vivo $(6,27)$, was also found to enhance PA release from BAE cells (Kuo, Dryjski, and Bjornsson, unpublished observations); whether its effect involves the same mechanism of action as that of the sulfonylureas remains to be elucidated.

Of the sulfonylureas investigated, glipizide was the most potent, causing as much as a 5.2-fold increase in released PA activity, while glyburide was the least potent, causing only a 1.3-fold increase in released PA activity. This difference in itself is of considerable interest as chemically these two compounds differ only in the end ring structure of the nonsulfonylurea arm of the molecules; glipizide has a pyrazine ring, glyburide a methoxy-chloro-phenyl ring. The other three sulfonylureas only have a methyl or chloride substitution in place of these ring containing arms. Considering the similar hypoglycemic potencies of glipizide and glyburide, these structural differences suggest first, that there are different structure-activity relationships at work for enhancing insulin and PA secretion, and second, that the pyrazine-containing arm enhances the fibrinolytic potential of sulfonylureas, while the methoxychloro-phenyl ring inhibits it.

The fibrin plate assay used in this study, although sensitive and reproducible, does not distinguish between the different types of plasminogen activators made by the BAE cells and which may be induced by the sulfonylureas. However, zymogram studies using SDS-PAGE gels with copolymerized gelatin and plasminogen showed that no new species of endothelial cell-derived PA were induced by the sulfonylureas. Both control and sulfonylurea-treated cells produced four discernible bands on the zymograms. Similar multiple band PA profiles have been reported by other investigators $(30,31)$. None of the lysis zones comigrated with standard UK, but one of the lysis zones on the zymograms corresponded to purified melanoma tPA, i.e., the 55,000-mol wt band (Fig. 7); its identity as tPA was verified by immunoprecipitation studies (Fig. 8). The major band on the SDS-PAGE zymograms was the 40,000 mol wt band (Fig. 7), which in immunoprecipitation experiments followed by SDS-PAGE zymography was shown to be a urokinase-type PA (Fig. 8). Thus our results reflect primarily the effects of sulfonylureas on urokinase-type PA. This species is similar to that reported earlier by Laug (32) and Levin and Loskutoff (33), who found this species to be the major PA species in BAE cells, and probably is a pro-urokinase (34). However, since tPA is thought to be the major circulating PA species in human beings (1), the extent to which sulfonylureas will stimulate tPA synthesis by the human vascular endothelium will require further investigation. Other higher molecular weight bands observed on the SDS-PAGE zymograms are likely to represent the respective PA-PAI complexes, in agreement with results of other investigators $(21,30,31,35)$.

The results of the reverse fibrin autography studies showed continuous secretion of PAI for at least $48 \mathrm{~h}$ from both the control cells and the sulfonylurea-treated cells. This PAI spe- 
cies had a molecular weight of $\sim 45,000$, which is similar to that reported earlier $(21,35,36)$, and most likely represents a latent form that can be activated in the presence of denaturants (36). No significant amounts of the fast-acting PAI were detected in mixing experiments involving conditioned medium and the standard TPA and UK, followed by fibrin plate assay or reverse fibrin autography. This finding is in general agreement with a report by Hekman and Loskutoff (36) that $>95 \%$ of BAE PAI is in a latent form. The sulfonylurea treatment appeared to decrease the amount of released PAI as evaluated by the reverse fibrin autography (Fig. 9). However, the present investigations do not allow further interpretation of the data, such as a possible decreased rate of synthesis of PAI. In this regard it is of interest to note that two sulfonylureas have been reported to normalize diabetic patients' fibrinolytic activity by decreasing PAI activity, as determined by a clot lysis test (9). However, it is also possible that the sulfonylureas in the present cell culture studies might have altered the distribution of PAI between free species and PA-PAI complex species due to the increased amounts of both tPA and UK. Which mechanism is operative and how much changes in PAI secretion, if any, contribute to the overall enhanced PA activity remains to be elucidated.

In summary, the present studies have unequivocally demonstrated that sulfonylureas are potent inducers of PA synthesis and secretion by bovine vascular endothelial cells. Similar results have been observed in sulfonylurea-treated human iliac arterial and venous endothelial cells (Kuo, Dryjski, and Bjornsson, unpublished observations). These results suggest that this PA stimulation is the major mechanism of action underlying the in vivo fibrinolytic effect of these agents, although the present studies have not been conclusive regarding the contribution of a concurrent decrease in PAI secretion. These findings suggest that sulfonylureas may have significant antithrombotic effects, in addition to their hypoglycemic effects. Considering the disposition kinetics parameters and the usual clinical daily doses of the different sulfonylureas (37), the expected plasma concentrations of these agents are well within the effective concentrations found in these in vitro investigations. The results of the present studies also suggest that pharmacological enhancement of PA production may be a promising antithrombotic drug mechanism.

\section{Acknowledgments}

This study was supported in part by grant NIA T32 A 600029 from the National Institutes of Health, a grant from the Philip Van Every Foundation, and a grant-in-aid from the Upjohn Company. Dr. Kuo is a recipient of a Special Investigatorship from the Southeastern Pennsylvania Chapter of the American Heart Association.

\section{References}

1. Collen, D. 1980. On the regulation and control of fibrinolysis. Thromb. Haemost. 45:77-89.

2. Todd, A. S. 1959. The histological localisation of fibrinolysin activator. J. Pathol. Bacteriol. 78:281-283.

3. Binder, B. R., J. Spragg, and K. F. Austen. 1979. Purification and characterization of human vascular plasminogen activator derived from blood vessel perfusates. J. Biol. Chem. 254:1998-2003.

4. Camiolo, S., S. Thorsen, and T. Astrup. 1971. Fibrinogenolysis and fibrinolysis with tissue plasminogen activator, urokinase, streptokinase-activated human globulin and plasminogen. Proc. Soc. Exp. Biol. Med. 138:177-280.
5. Owen, C. A., and E. J. A. Bowie. 1982. Predisposing factors in thrombosis. In Thrombosis. H. C. Kwaan, and E. J. A. Bowie, editors. W. B. Saunders Co., Philadelphia. 29-56.

6. Prowese, C. V., and J. D. Cash. 1984. Physiologic and pharmacologic enhancement of fibrinolysis. Semin. Thromb. Hemost. 10:51-60.

7. Astrup, T. 1956. Fibrinolysis in the organism. Blood. 11:781806.

8. Fearnley, G. R., R. Chakrabarti, and C. T. Vincent. 1960. Effects of the sulfonylureas on fibrinolysis. Lancet. 2:622-625.

9. Almer, L.-O. 1984. Effect of chlorpropamide and gliclazide on plasminogen activator activity in vascular walls in patients with maturity onset diabetes. Thromb. Res. 35:19-25.

10. Nilsson, I. M. 1976. Fibrinolysis in diabetes and obesity. In Advances in Coagulation, Fibrinolysis, Platelet Aggregation and Atherosclerosis. First Proceedings of the European Symposium. A. Strano, editor. CEPI, Rome. 95-105.

11. Fuchs, H. E., H. Berger, Jr., and S. V. Pizzo. 1985. Catabolism of human tissue plasminogen activator in mice. Blood. 65:539-544.

12. Deutsch, D. G., and E. T. Mertz. 1970. Plasminogen: purification from human plasma by affinity chromatography. Science (Wash. DC). 170:1095-1096.

13. Gospodarowicz, D., J. S. Moran, and L. Braun. 1977. Control of proliferation of bovine vascular endothelial cells. J. Cell Physiol. 91:377-386.

14. Gospodarowicz, D., and G.-M. Lui. 1981. Effect of substrate and fibroblast growth factor on the proliferation in vitro of bovine aortic endothelial cells. J. Cell. Physiol. 109:69-81.

15. Jaffe, E. A., L. W. Hoyer, and R. L. Nachman. 1973. Synthesis of antihemophilic factor antigen by cultured human endothelial cells. J. Clin. Invest. 52:2757-2764.

16. Smith, P. K., R. I. Krohn, G. T. Hermanson, A. K. Mallia, F. H. Gartner, M. D. Drobenzano, E. K. Fujimato, N. M. Goeke, B. J. Olson, and D. C. Klenk. 1985. Measurement of protein using bicinchoninic acid. Anal. Biochem. 150:76-85.

17. Hamilton, J. A., and J. Slywka. 1981. Stimulation of human synovial fibroblast plasminogen activator production by mononuclear cell supernatants. J. Immunol. 126:851-855.

18. Levin, E. G. 1983. Latent tissue plasminogen activator produced by human endothelial cells in culture: evidence for an enzymeinhibitor complex. Proc. Natl. Acad. Sci. USA. 80:6804-6809.

19. Granelli-Piperno, A., and E. Reich. 1978. A study of protease and protease-inhibitor complex in biological fluid. J. Exp. Med. 148:223-234.

20. Heussen, C., and E. B. Dowdle. 1980. Electrophoretic analysis of plasminogen activators in polyacrylamide gels containing sodium dodecyl sulfate and copolymerized substrates. Anal. Biochem. 102:196-202.

21. Loskutoff, D. J., J. A. van Mourik, L. A. Erickson, and D. A. Lawrence. 1983. Detection of an unusually stable fibrinolytic inhibitor produced by bovine endothelial cells. Proc. Natl. Acad. Sci. USA. 80:2956-2960.

22. Erickson, L. A., D. A. Lawrence, and D. J. Loskutoff. 1984. Reverse fibrin autography: a method to detect and partially characterize protease inhibitors after sodium dodecyl sulfate-polyacrylamide electrophoresis. Anal. Biochem. 137:454-463.

23. Laug, W. E. 1983. Ethyl alcohol enhances plasminogen activator secretion by endothelial cells. JAMA (J. Am. Med. Assoc.) 250:772-776.

24. Fearnley, G. R., C. T. Vincent, and R. Chakrabarti. 1959. Reduction of blood fibrinolytic activity in diabetes mellitus by insulin. Lancet. 2:1067.

25. Fearnley, G. R., R. Chakrabarti, and P. R. D. Avis. 1963. Blood fibrinolytic activity in diabetes mellitus and its bearing on ischemic heart disease and obesity. Br. Med. J. 1:921-923.

26. Fearnley, G. R., and R. Chakrabarti. 1964. Pharmacological enhancement of fibrinolytic activity in blood. J. Clin. Pathol. 17:328332.

27. Fearnley, G. R., R. Chakrabarti, E. D. Hockıng, and J. F. 
Evans. 1967. Fibrinolytic effects of biguanides plus ethyloestrenol in occlusive vascular disease. Lancet. 2:1008-1011.

28. Levin, E. G., U. Marzec, J. Anderson, and L. A. Harker. 1984. Thrombin stimulates tissue plasminogen activator release from cultured human endothelial cells. J. Clin. Invest. 74:1988-1955.

29. Hamilton, J. A. 1982. Stimulation of the plasminogen activator activity of human synovial fibroblasts by retinoids. Arthritis Rheum. 25:432-440.

30. Levin, E. G., and D. J. Loskutoff. 1982. Cultured bovine endothelial cells produce both urokinase and tissue-type plasminogen activators. J. Cell Biol. 94:631-636.

31. Loskutoff, D. J. 1984. The fibrinolytic system of cultured endothelial cells: deciphering the balance between plasminogen activation and inhibition. In Progress in Fibrinolysis. Vol. 7. J. F. Davidson, M. B. Donati, and S. Coccheri, editors. Churchill Livingstone, New York. 15-22.

32. Laug, W. E. 1981. Secretion of plasminogen activators by cul- tured bovine endothelial cells: partial purification, characterization and evidence of multiple forms. Thromb. Haemost. 45:219-224.

33. Levin, E. G., and D. J. Loskutoff. 1980. Serum-mediated suppression of cell-associated plasminogen activator activity in cultured endothelial cells. Cell. 22:701-707.

34. Loskutoff, D. J. 1986. The fibrinolytic system of cultured endothelial cells: insights into the role of endothelium in thrombolysis. In Vascular Endothelial Cells in Hemostasis and Thrombosis. M. A. Gimbrone, editor. Churchill Livingstone, New York. 120-141.

35. van Mourik, J. A., D. A. Lawrence, and D. J. Loskutoff. 1984. Purification of an inhibitor of plasminogen activator (antiactivator) synthesized by endothelial cells. J. Biol. Chem. 259:14914-14921.

36. Hekman, C. M., and D. J. Loskutoff. 1985. Endothelial cells produce a latent inhibitor of plasminogen activator that can be activated by denaturants. J. Biol. Chem. 260:11581-11587.

37. Asmal, A. C., and A. Marble. 1984. Oral hypoglycemic agents. An update. Drugs. 28:62-78. 